\title{
From painful breast erythematic lesions to incidental mammary findings
}

\author{
Florica Sandru' ${ }^{1,2}$, Ana Valea ${ }^{3,4}$, Simona Elena Albu ${ }^{1,5}$, Mihai Cristian Dumitrascu ${ }^{1,5}$, \\ Rene Baloescu' ${ }^{6}$, Ana Maria Alexandra Stanescu', Mara Carsote ${ }^{1,6}$ \\ 1"Carol Davila" University of Medicine and Pharmacy, Bucharest, Romania \\ Elias Emergency University Hospital, Bucharest, Romania \\ ${ }^{3}$ Clinical County Hospital, Cluj-Napoca, Romania \\ 4"Iuliu Hatieganu” University of Medicine and Pharmacy, Cluj-Napoca, Romania \\ ${ }^{5}$ Emergency University Hospital, Bucharest, Romania \\ 6"C.I. Parhon" National Institute of Endocrinology, Bucharest, Romania
}

\begin{abstract}
Introduction. High prolactin may cause central hypogonadism including osteoporosis and breast secretion but also rare manifestations like increased androgens in females or galactocele. A part from high prolactin related large cystic incidental mammary findings, the breast cysts may be associated with infections, local trauma and hemorrhage of priory benign cystic disease or solid tumors.

Method. We introduce different clinical aspects of breast nodules with benign appearance, either symptomatic like painful large cyst with local inflammation elements or asymptomatic as an incidental finding. This is a cases series from a multidisciplinary perspective.

Cases data. The patients' age is between 43 and 62 years. The youngest female presented a large left cyst after a potential local trauma with local inflammation signs which were released after liquid evacuation. The oldest patient had bilateral mammary micro-cysts with a good prognostic as incidental finding.

Conclusion. Benign breast lesions of adult females may associate local skin changes as redness and increased temperature or they may be completely asymptomatic, being detected as incidental findings. Regardless the scenario, the index of malignancy suspicion is always necessary because of heterogeneous presentation and increased incidence of mammary cancer.
\end{abstract}

Keywords: mammary cyst, breast nodule, incidentaloma, incidental finding, erythema

\section{INTRODUCTION}

Incidental imaging findings, a "fashionable" multidisciplinary topic, include affects endocrine organs like hypophiseal and adrenals glands but generally any organ with parenchyma $(1,2,3)$. A recent large meta-analysis including 240 studies of different types showed that incidental findings are found more than one third at investigations like computed tomography or magnetic resonance imagery (2). The rate of malignancy varies with the inclusion criteria of studied population (2). It is low for pituitary incidentalomas but it increases to $5 \%$ for adrenal incidentalomas based on some analyses $(2,4,5)$. Usually there is no hormonal activity at the level of an incidentaloma but controversies around the definition are still running $(4,6,7)$. Positive endocrine activity is an indication of tumor removal $(8,9)$. The exception is a prolactinoma confirmation in which case medical therapy with dopamine agonists is the first line therapy unless severe compression symptoms are confirmed thus requiring neurosurgery $(8,9)$. High prolactin may cause central hypogonadism including osteoporosis and breast secretion but also rare manifestations like increased androgens in females or galactocele $(10,11)$. A part from high prolactin - related large cystic incidental mammary findings, the breast cysts may be associated with infections, local trauma and hemorrhage of priory benign cystic disease or solid tumors (12). Other large cysts have been described at the level of pineal and pituitary and adrenals as well as 
thyroid gland of different underling pathogenesis pathways $(13,14,15)$.

\section{AIM}

We introduce different clinical aspects of breast nodules with benign appearance, either symptomatic like painful large cyst with local inflammation elements or asymptomatic as an incidental finding.

\section{METHOD}

This is a cases series from a multidisciplinary perspective. The patients agreed for anonymously presentation of their medical data.

\section{CASES DATA}

\section{Case 1}

This is a 43 year old non smoking female admitted for painful left breast with local rubor and calor since last week. The family medical history is negative. She had a recent surgery done for cervical hernia and she is under physical rehabilitation program. She had a history of benign cystic dysplasia of the breast a few years ago; since then she has intermittent mastalgia during menstruation without medication (regular menses). She had two normal births more than 15 years ago and she does not use oral contraceptives. She also currently accuses intermittent chest pain and parestesia. She was seen in several medical departments until admission to endocrinology. At presentation, signs of inflammation are positive for the area of left breast. Normal total calcium levels of $9.8 \mathrm{mg} / \mathrm{dl}$ (normal between 8.5 and $10.3 \mathrm{mg} / \mathrm{dl}$ ) excluded a potential anomaly of calcium metabolism. Electrocardiogram showed sinus rhythm of 72/minute; in addition she had normal blood pressure (Figure 1). The assays pointed normal TSH (thyroid stimulating hormone), testosterone, and prolactin (of $8 \mathrm{ng} / \mathrm{ml}$, normal between 3.3 and $26 \mathrm{ng} / \mathrm{ml}$ ), while blood inflammation markers showed normal fibrinogen of $411 \mathrm{mg} / \mathrm{dl}$ (normal between 200 and $500 \mathrm{mg} / \mathrm{dl}$ ), C reactive protein of $0.158 \mathrm{mg} / \mathrm{dl}$ (normal between 0 and $0.5 \mathrm{mg} /$ dl) and a small increase of erythrocytes sedimentation rate of $26.7 \mathrm{~mm} /$ at 1 hour (normal between 1 and $25 \mathrm{~mm} / 1-\mathrm{h}$ ). Breast ultrasound showed left mammary gland with mix structure and multiple cysts or micro-cysts of $9.8 / 4.3 \mathrm{~mm}$ (millimeter), $37.2 / 21.2 / 28.7 \mathrm{~mm}$ (well shaped with regular margins), of $12.7 / 7.4 \mathrm{~mm}$, and multiple other cysts of less than $5 \mathrm{~mm}$ and also a solid nodule of $9.8 / 4.3$ $\mathrm{mm}$ with hypo-echoic pattern and a cluster of micro-cysts (Figure $2 \mathrm{~A}, \mathrm{~B}, \mathrm{C}$ ). A Similar structure was confirmed at the level of right breast with multiple cysts, the largest of $13.5 / 7.1 \mathrm{~mm}$, respective $8.8 / 8.3$ $\mathrm{mm}$ (Figure 3). Despite the fact that the patient was offered oral anti- inflammatory drugs, the rapid and

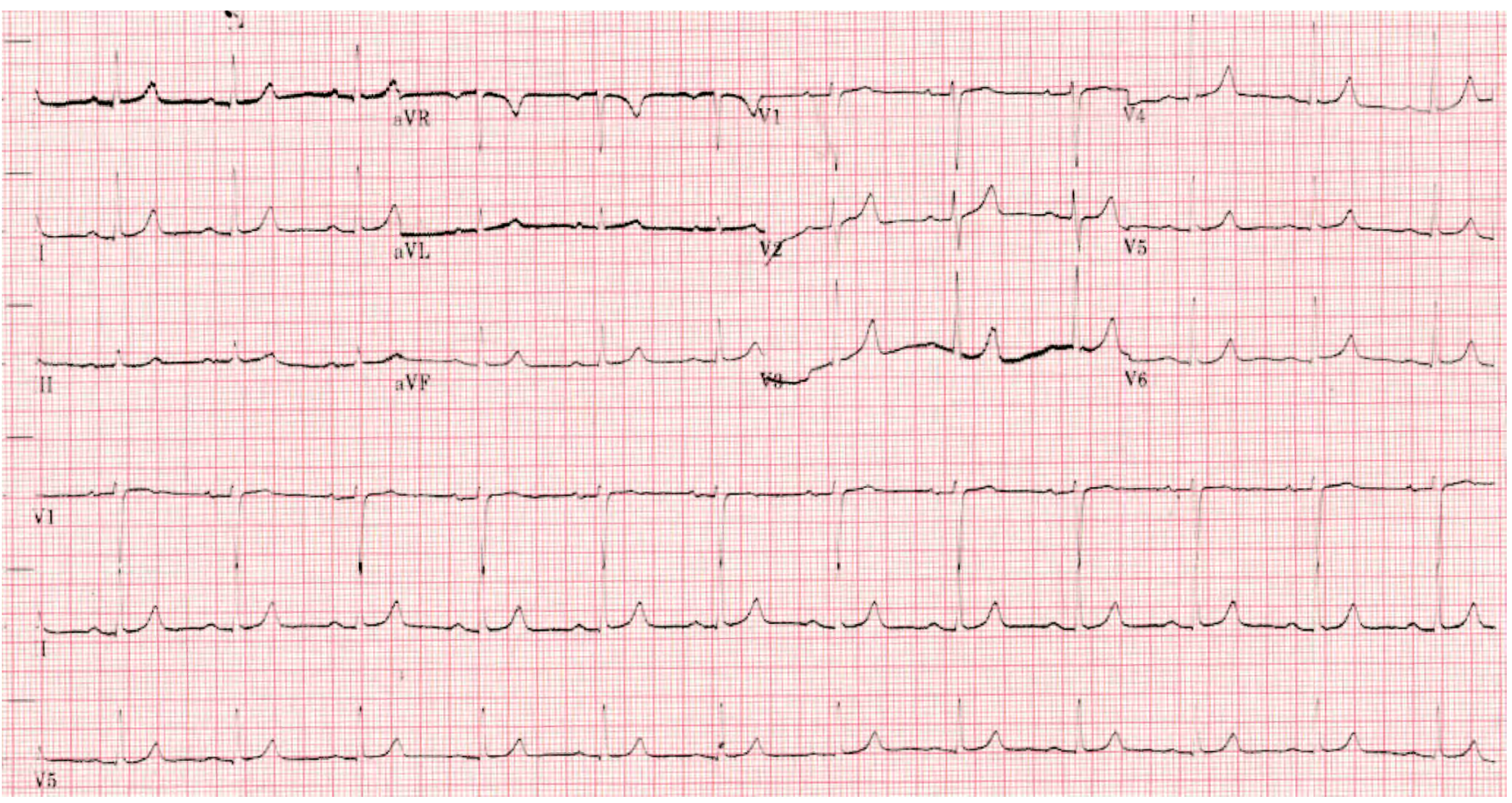

FIGURE 1. Normal electrocardiogram on a 43-year old female admited for non-specific chest pain in addition to nonbreastfeeding inflamation at the level of left breast 


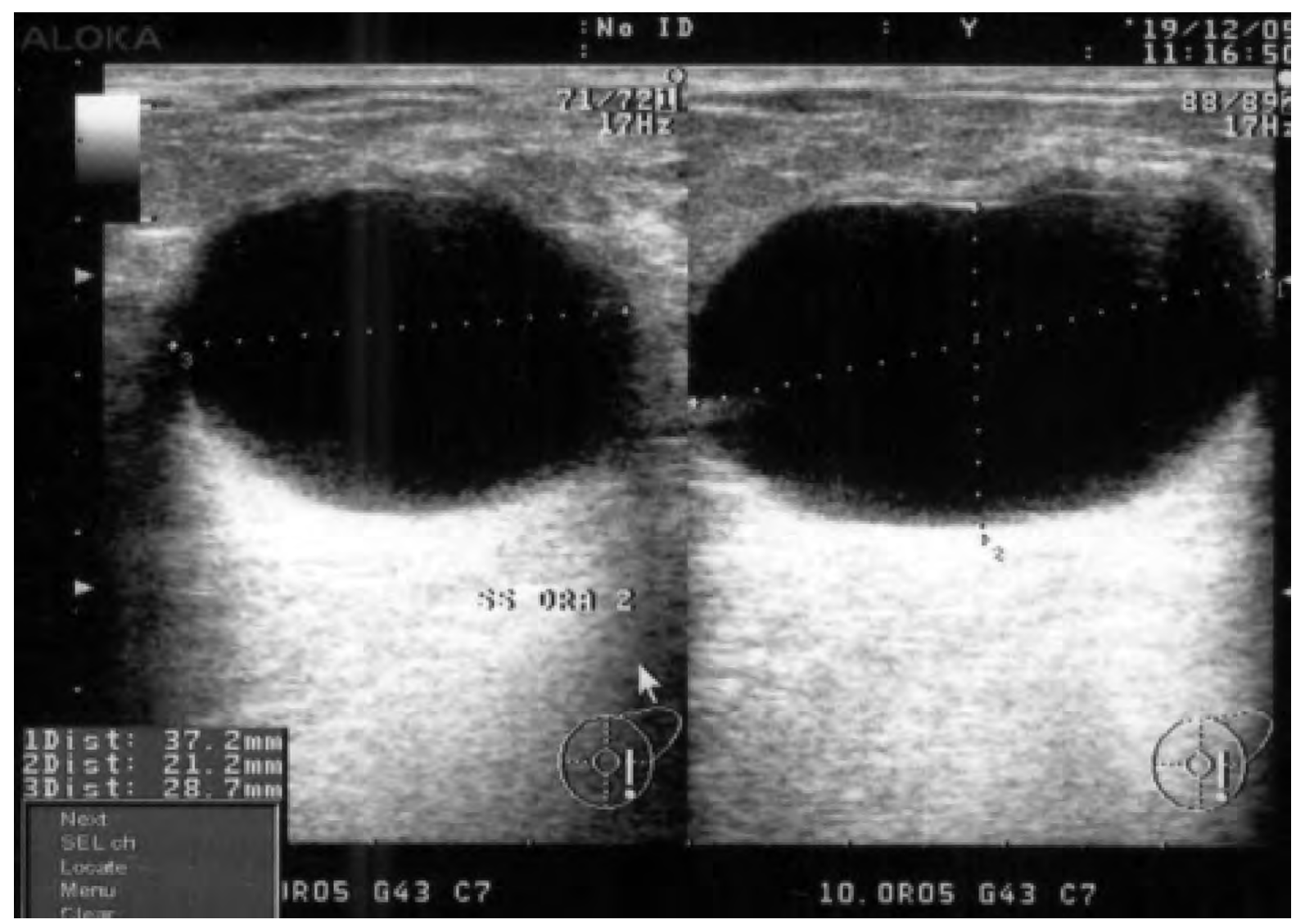

FIGURE 2A. The largest cyst of $37.2 / 21.2 / 28.7 \mathrm{~mm}$ (well shaped with regular margins)

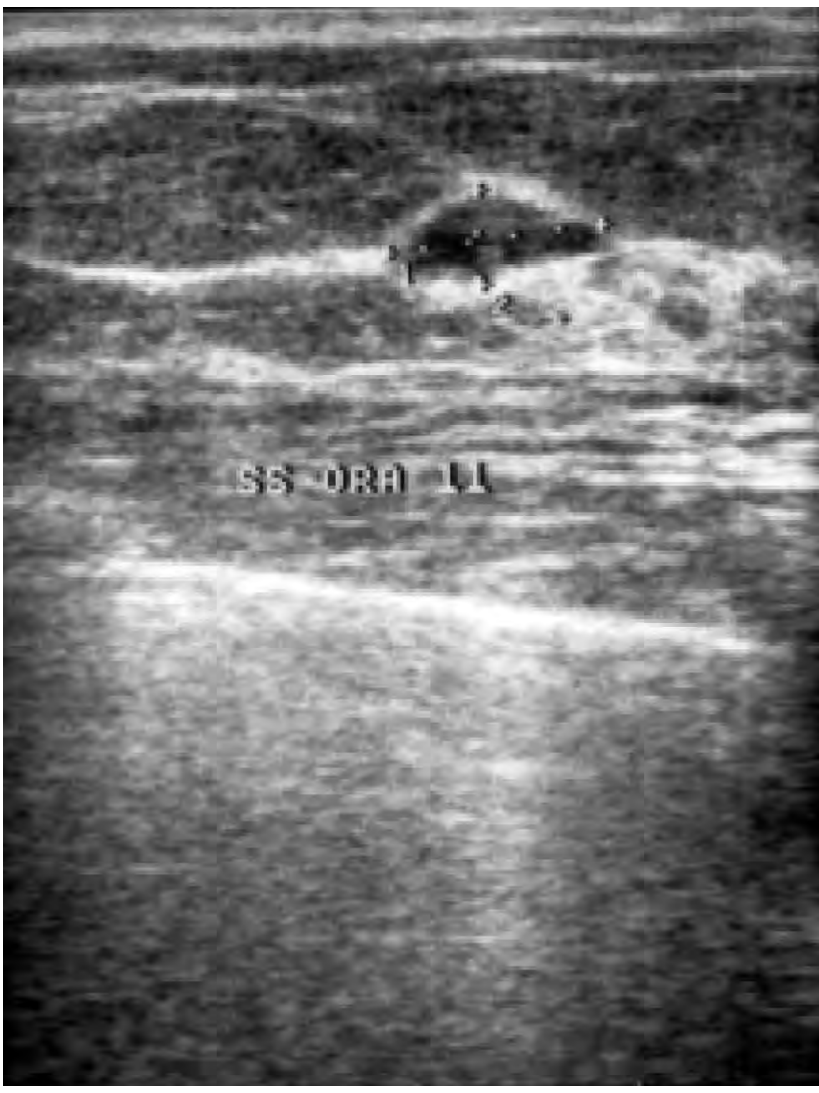

FIGURE 2B. A solid nodule of $9.8 / 4.3 \mathrm{~mm}$ with hypoechoic pattern and a cluster of micro-cysts

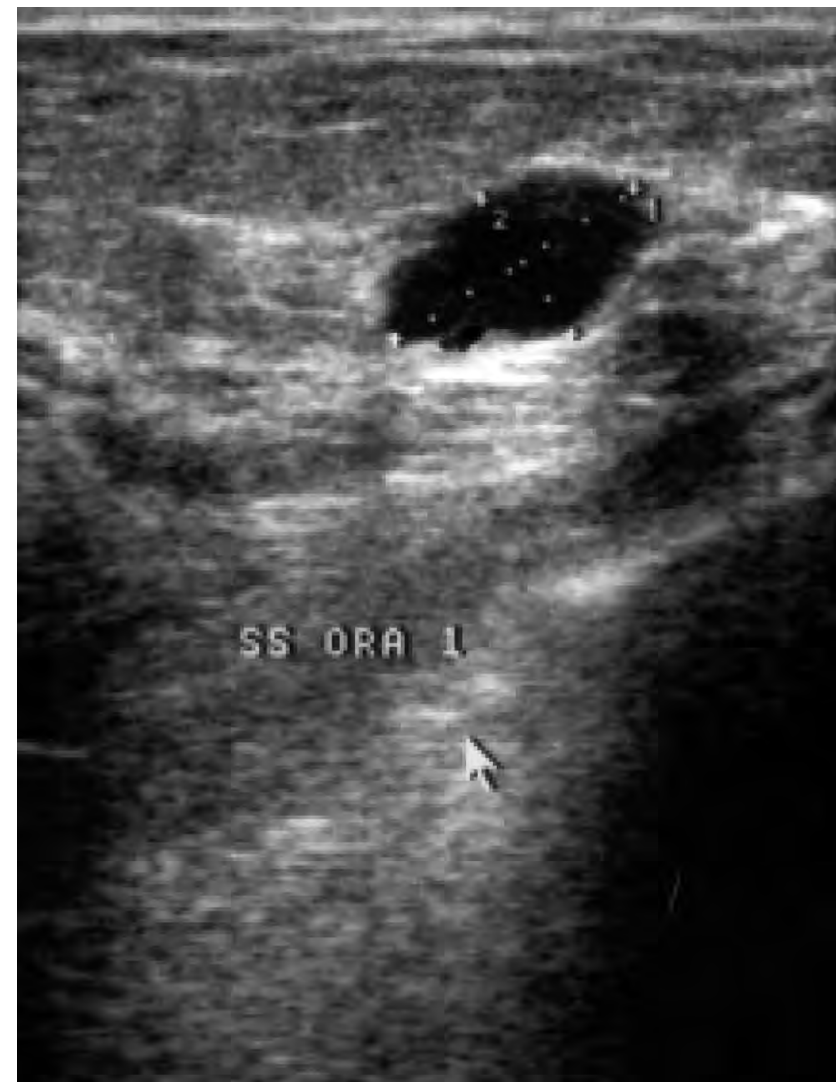

FIGURE 2C. A cyst of $12.7 / 7.4 \mathrm{~mm}$

FIGURE 2. Multiple cysts on a cystic dysplasia background. 43-year old female presenting with acute pain and redness at the level of left breast 
complete remission of the symptoms was seen only at cyst evacuation through fine needle aspiration. No atypia was registered at cytological report.

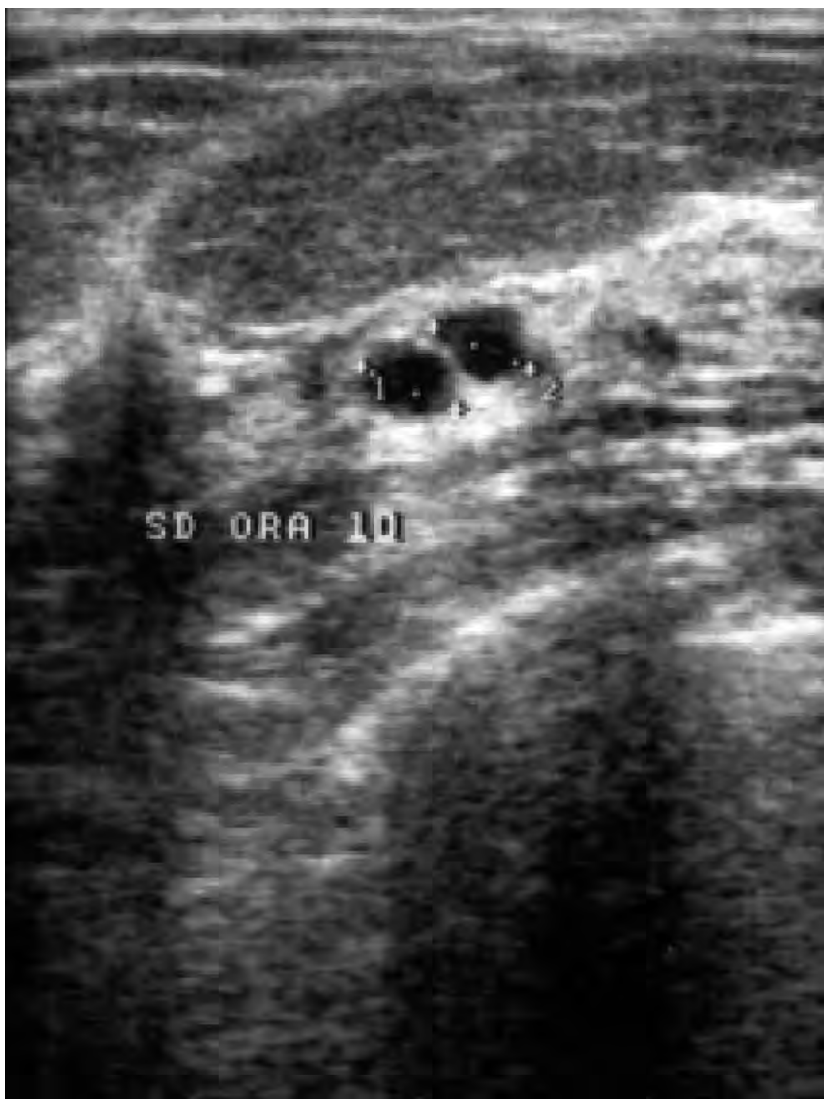

FIGURE 3. Right mammary gland with a cyst of $13.5 / 7.1 \mathrm{~mm}$

\section{Case 2}

This is a 55-year old female who was admitted for mineral metabolism evaluation because of recurrent kidney stones. She recently entered menopause without specific vasomotor symptoms. The family medical history is not significant. The clinical examination is within normal parameters inclusive body mass index. The blood parameters were within normal parameters including parathormone. Screening mammogram was done and revealed an incidental opacity of heterogeneous structure with partially irregular shape, the largest diameters of $80 / 90 \mathrm{~mm}$, probably a myelolipoma (Figure 4). Prolactin and TSH were normal. The patient refused further biopsy and investigations.

\section{Case 3}

This is a 62-year old non-smoking female known with pituitary incidentaloma since the last 5 years. She had menopause at age of 50 years without hormone replacement therapy. Endocrine pituitary profile is normal, magnetic resonance imagery showed a stationary micronodule of $5 \mathrm{~mm}$. A screening breast ultrasound was done and it revealed a small cyst at the level of right breast of $4.7 / 3.4 \mathrm{~mm}$, and a left microcyst of $7.4 / 3.2 \mathrm{~mm}$, without other anomalies (BIRADS 2 bilateral) (Figure 5). Mammogram confirmed the score. The patient was further follow-up.
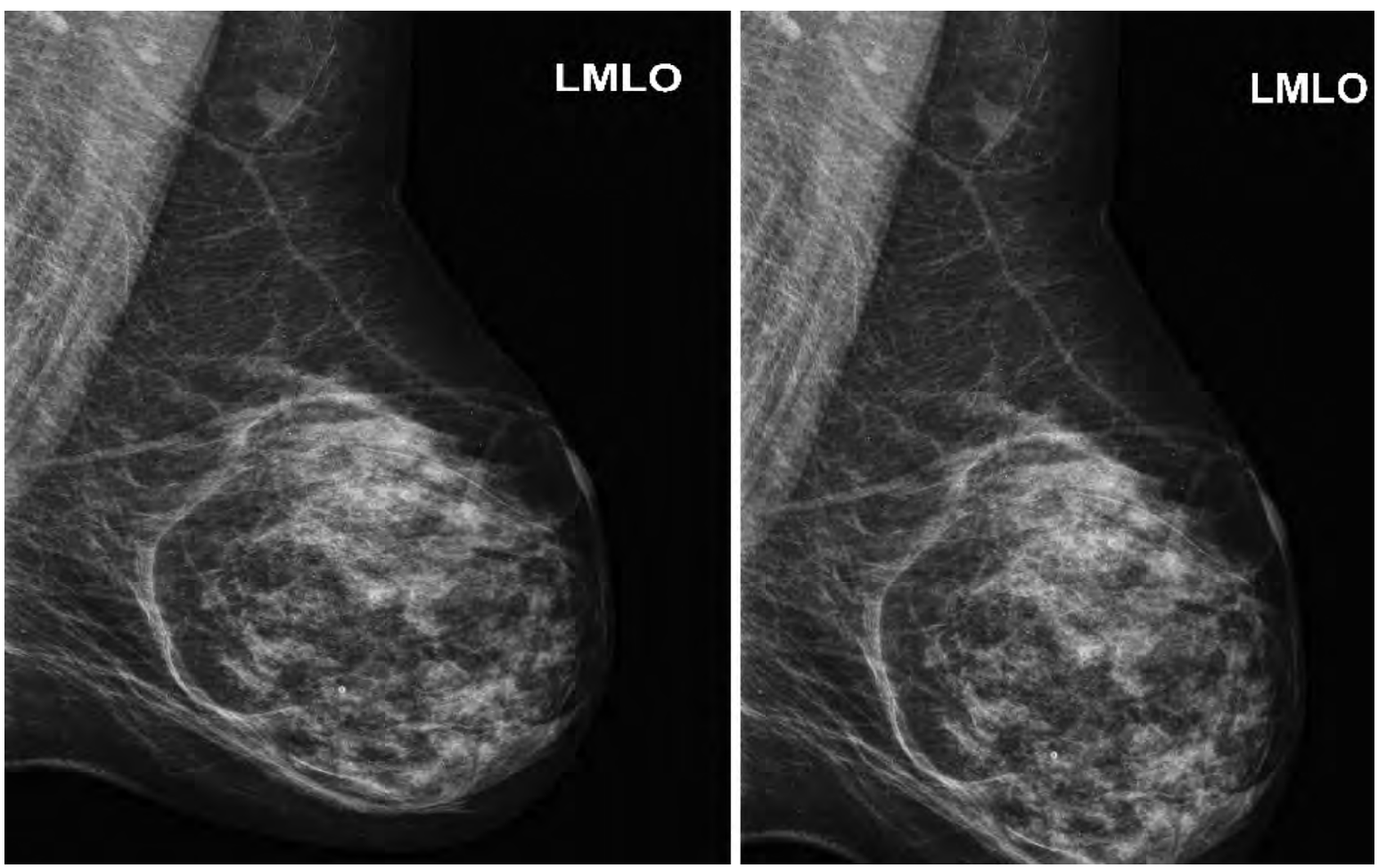

FIGURE 4. Left breast mammogram. Incidental opacity of heterogeneous structure with partially irregular shape, the largest diameters of $80 / 90 \mathrm{~mm}$, probably a myelolipoma on a 55-year old female 


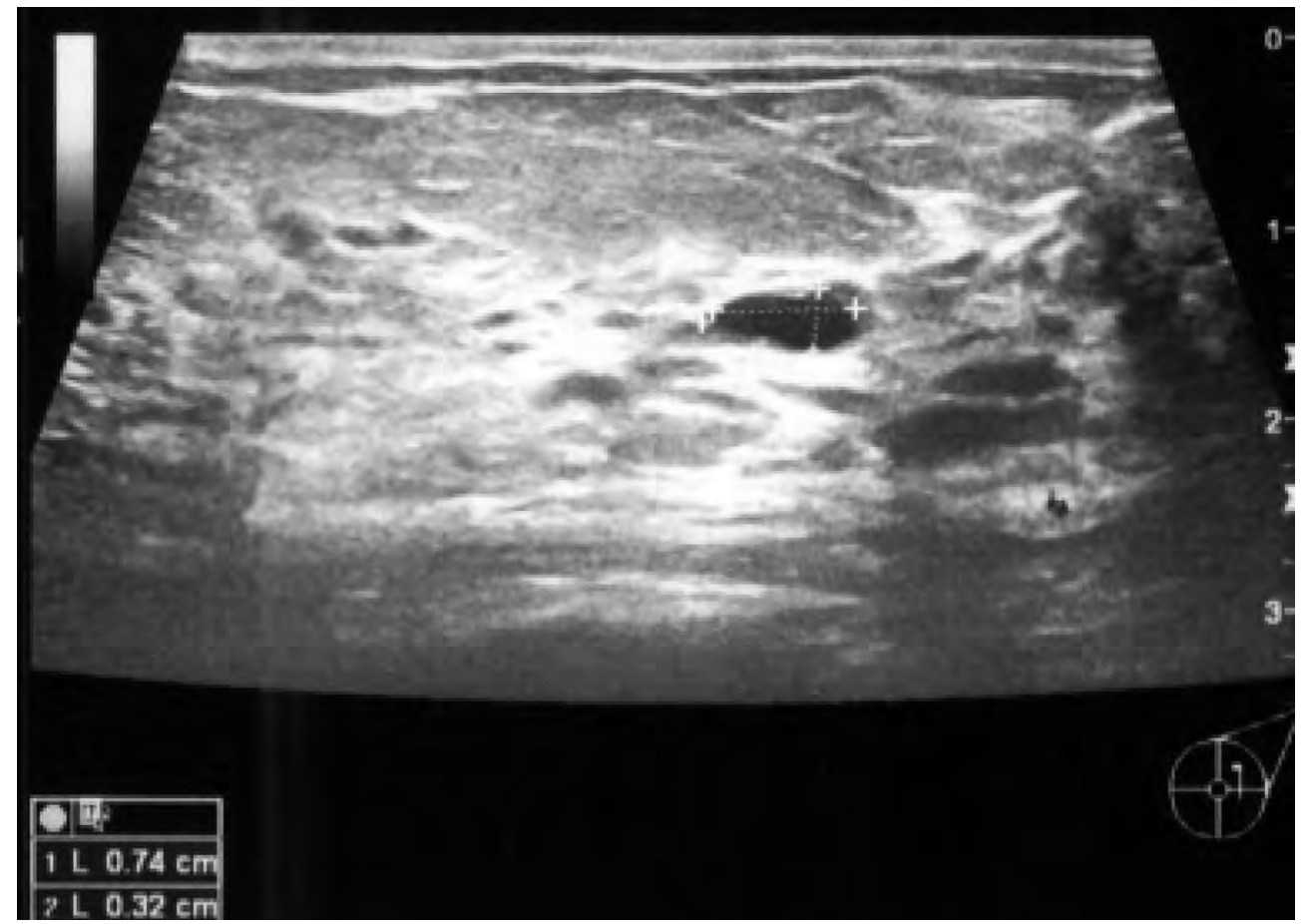

FIGURE 5A. A small left microcyst of $7.4 / 3.2 \mathrm{~mm}$, without other anomalies (BIRADS 2 bilateral)

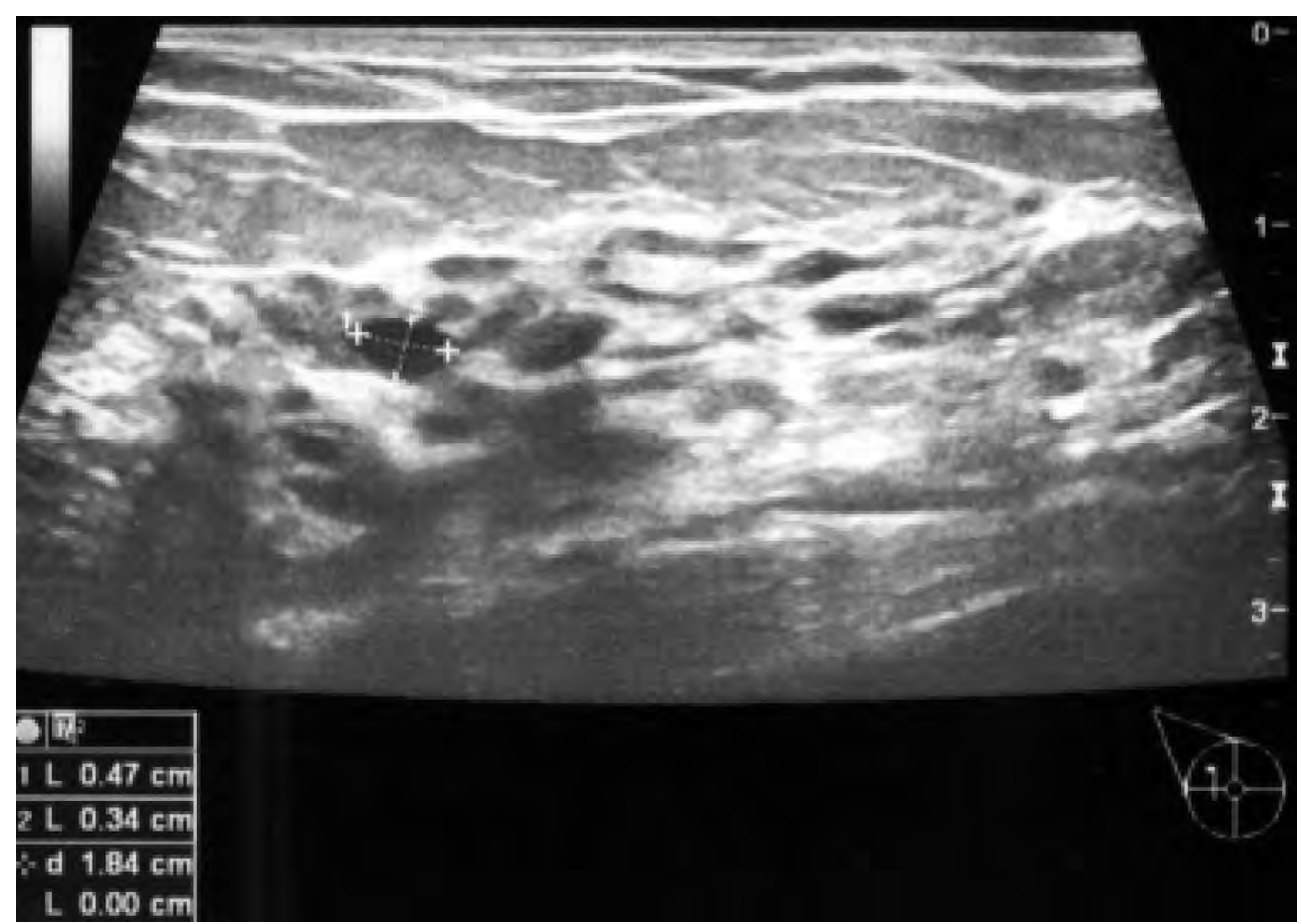

FIGURE 5B. A cyst at the level of right breast of $4.7 / 3.4 \mathrm{~mm}$

FIGURE 5. This is the breast ultrasound assessment of a 62-year old non-smoking female

\section{DISCUSSION}

We introduce some practical points related to the cases we introduced. The first case had more probably a post-traumatic hemorrhage at the level of a previously small cyst with local inflammation. The liquid evacuation was salutary for the symptoms. The lack of connection with menstruation, pregnancy or breastfeeding is suggestive as etiologic context $(16,17,18)$. The second case was not confirmed with calcium metabolism anomalies thus screening for osteoporosis was unnecessary at this age knowing the short time since menopause and lack of clinical risk factors $(19,20)$. No profile lumbar spine X-Ray screening was either consider useful (21). The mylolipoma is a rare finding of in- 
cidentaloma type in this case (1). A limited number of reports showed the association with breast cancer or ovarian lesions while this type of tumour is more frequent found at adrenal level $(22,23,24)$. The risk of malignancy for a breast incidentaloma is high of $42 \%$ while for thyroid or ovarian incidentaloma is up to $25 \%$ for unselected series (2). The third patient had a pituitary incidentaloma. One of ten adults may have this harmless diagnosis and it does not increase the risk of mammary lesions which were incidental (1). The menopause - detected cysts were not suspicion for a breast malignancy in this particular case due to their imaging features. However, rapidly growing breast cysts

\section{REFERENCES}

1. Gheorghisan-Galateanu AA, Carsote M, Valea A. Incidentaloma: From general practice to specific endocrine frame. J Pak Med Assoc. 2017; 67(6):917-922.

2. O'Sullivan JW, Muntinga T, Grigg S, loannidis JPA. Prevalence and outcomes of incidental imaging findings: Umbrella review. BMJ. 2018 Jun 18;361:k2387.

3. Gheorghiu M, Hortopan D, Dumitrascu A, Caragheorgheopol A, Stefanescu A, Trifanescu R, Niculescu D, Baciu I, Carsote M, Poiana C, Badiu C, Coculescu M. Age-related endocrine tumors: nonfunctioning adrenal tumors as compared to pituitary adenomas. Acta Endocrinologica, 2009; V(3):371-384

4. Lopez AG, Fraissinet F, Lefebvre H, Brunel V, Ziegler F. Pharmacological and analytical interference in hormone assays for diagnosis of adrenal incidentaloma. Ann Endocrinol (Paris). 2019;80(4):250-258.

5. Carsote M, Chirita C, Dumitrascu A, Fica S, Poiana C. Pituitary incidentalomas - How often is too often? Journal of Medicine and Life, 2009; 2(1):92-97.

6. Fassnacht M, Arlt W, Bancos I, Dralle H, Newell-Price J, Sahdev A, Tabarin A, Terzolo M, Tsagarakis S, Dekkers OM. Management of adrenal incidentalomas: European Society of Endocrinology Clinical Practice Guideline in collaboration with the European Network for the Study of Adrenal Tumors. Eur J Endocrinol. 2016;175(2):G1-G34.

7. Poiana C, Chirita C, Carsote M, Hortopan D, loachim D, Corneci CM, Stanescu B. Adrenal and Pituitary Incidentalomas in a Case of Cushing's Syndrome. Chirurgia 2013; 6(108):886-891.

8. Freda PU, Beckers AM, Katznelson L, Molitch ME, Montori VM, Post $K D$, Vance ML; Endocrine Society. Pituitary incidentaloma: An endocrine society clinical practice guideline. J Clin Endocrinol Metab. 2011;96(4):894-904.

9. Paduraru DN, Nica A, Carsote M, Valea A. Adrenalectomy for Cushing's syndrome: Do's and don'ts. Journal of Medicine and Life. 2016; 4(9):334-341.

10. Dogan BA, Berker D, Arduc A, Tuna MM, Nasiroglu NI, Karakiliç E, Basaran MN, Isik S, Tutuncu Y, Unal M, Guler S. Insulin resistance and androgen levels in eugonadic and hypogonadic women with prolactinoma. Minerva Endocrinol. 2016 Jun;41(2):175-82.

11. Poiana C, Chirita C, Carsote M, Hortopan D, Goldstein A. Galactocele and prolactinoma - A pathogenic association? Maturitas. 2009; 62(1):98-102.

12. Kim HS, Kim YH, Park SB. A papilloma in a large cyst of the breast: $A$ case report. Int J Surg Case Rep. 2019;55:1-3.

13. Poiana C, Carsote M, Chirita C, Terzea D, Paun S, Beuran M. Giant adrenal cyst: Case study. J Med Life 2010; 3(3):308-313.

14. Májovský M, Netuka $D$, Beneš $V$. Is surgery for pineal cysts safe and effective? Short review. Neurosurg Rev. 2018;41(1):119-124. may be found in in menopause and they may underline a breast cancer (25). Moreover, in menopause screening of breast cancer is preferable to be done with mammogram as first step (26).

\section{CONCLUSIONS}

Benign breast lesions of adult females may associate local skin changes as redness and increased temperature or they may be completely asymptomatic, being detected as incidental findings. Regardless the scenario, the index of malignancy suspicion is always necessary because of heterogeneous presentation and increased incidence of mammary cancer.

Conflict of interest: none declared Financial support: none declared

15. Carsote M, Ghemigian A, Terzea D, Gheorghisan-Galateanu AA, Valea A. Cystic adrenal lesions: Focus on pediatric population (a review). Clujul Medical. 2017;90(1):5-12.

16. Seo KJ, Whang IY. Apocrine Ductal Carcinoma In Situ Presenting as a Large, Cystic Breast Mass: An Uncommon Presentation of a Rare Breast Lesion. Breast J. 2017;23(5):594-595.

17. Poiana C, Carsote M, Trifanescu R, Terzea D, Croitoru A. Case study of Appendiceal Carcinoid during Pregnancy. J Med Life 2012; 15;5(3):325-32.

18. Poiana C, Musat M, Carsote M, Chirita C. Premenstrual dysphoric disorder: Neuroendocrine interferences, Rev Med Chir Soc Med Nat lasi. 2009;113(4):996-1000.

19. US Preventive Services Task Force, Curry SJ, Krist AH, Owens DK, Barry MJ, Caughey AB, Davidson KW, Doubeni CA, Epling JW Jr, Kemper AR, Kubik M, Landefeld CS, Mangione CM, Phipps MG, Pignone M, Silverstein M, Simon MA, Tseng CW, Wong JB. Screening for Osteoporosis to Prevent Fractures: US Preventive Services Task Force Recommendation Statement. JAMA. 2018;319(24):2521-2531.

20. Poiana C, Radoi V, Carsote M, Bilezekian J. New Clues that May Link Osteoporosis to the Circulating Lipid Profile. Bone Research 2013 ;1(3):260-266,

21. Poiana C, Carsote M, Radoi V, Mihai A, Capatina C. Prevalent osteoporotic fractures in 622 obese and non-obese menopausal women. Journal of Medicine and Life. 2015;8(4):462-466.

22. Varone V, Ciancia G, Bracale U, Merola G, Vetrani A, Pettinato G, Cozzolino I. Multidisciplinary diagnostic approach combining fine needle aspiration, core needle biopsy and imaging features of a presacral myelolipoma in a patient with concurrent breast cancer. Pathol Res Pract. 2015;211(3):261-3.

23. Poiana C, Virtej I, Carsote M, Banceanu M, Sajin M, Stanescu B, loachim D, Hortopan D, Coculescu M. Virilising Sertoli-Leydig cell tumour associated with thyroid papillary carcinoma: Case report and general considerations. Gynecol Endocrinol 2010;26(8):617-622.

24. Kalafatis P. Bilateral giant adrenal myelolipoma and polycystic ovarian disease. Urol Int. 1999;63(2):139-43.

25. Salemis NS. Intracystic breast carcinoma. An important differential diagnosis in postmenopausal patients presenting with a rapidly growing breast cyst. Management and literature review. Breast Dis. 2018;37(4):219-224.

26. Depypere H, Desreux J, Pérez-López FR, Ceausu I, Erel CT, Lambrinoudaki I, Schenck-Gustafsson K, van der Schouw YT, Simoncini T, Tremollieres F, Rees M, EMAS. EMAS position statement: individualized breast cancer screening versus populationbased mammography screening programmes. Maturitas. 2014; 79(4):481-6. 